\title{
Evaluating Light Rain Drop Size Estimates from Multiwavelength Micropulse Lidar Network Profiling
}

\author{
SIMONE LOLLI \\ Joint Center for Earth Systems Technology, NASA Goddard Space Flight Center, Greenbelt, Maryland \\ ELLSWORTH J. WELTON \\ NASA Goddard Space Flight Center, Greenbelt, Maryland \\ JAMES R. CAMPBELL \\ Naval Research Laboratory, Monterey, California
}

(Manuscript received 4 March 2013, in final form 29 July 2013)

\begin{abstract}
This paper investigates multiwavelength retrievals of median equivolumetric drop diameter $D_{0}$ suitable for drizzle and light rain, through collocated 355-/527-nm Micropulse Lidar Network (MPLNET) observations collected during precipitation occurring 9 May 2012 at the Goddard Space Flight Center (GSFC) project site. By applying a previously developed retrieval technique for infrared bands, the method exploits the differential backscatter by liquid water at 355 and $527 \mathrm{~nm}$ for water drops larger than $\approx 50 \mu \mathrm{m}$. In the absence of molecular and aerosol scattering and neglecting any transmission losses, the ratio of the backscattering profiles at the two wavelengths ( 355 and $527 \mathrm{~nm}$ ), measured from light rain below the cloud melting layer, can be described as a color ratio, which is directly related to $D_{0}$. The uncertainty associated with this method is related to the unknown shape of the drop size spectrum and to the measurement error. Molecular and aerosol scattering contributions and relative transmission losses due to the various atmospheric constituents should be evaluated to derive $D_{0}$ from the observed color ratio profiles. This process is responsible for increasing the uncertainty in the retrieval. Multiple scattering, especially for UV lidar, is another source of error, but it exhibits lower overall uncertainty with respect to other identified error sources. It is found that the total error upper limit on $D_{0}$ approaches $50 \%$. The impact of this retrieval for long-term MPLNET monitoring and its global data archive is discussed.
\end{abstract}

\section{Introduction}

The primary objective of the National Aeronautics and Space Administration (NASA)'s Micropulse Lidar Network (MPLNET; Welton et al. 2001), a member of the Global Atmospheric Watch (GAW) Aerosol Lidar Observation Network (GALION; Hoff and Boesenberg 2008), is the depiction of cloud and aerosol particle distributions, utilizing a global and federated network of ground-based lidar instruments. Enhancing the project, efforts are presently ongoing toward the integration of ultraviolet (UV; $355 \mathrm{~nm})$, eye-safe, and autonomous lidar

Corresponding author address: Simone Lolli, NASA Goddard Space Flight Center, Mail Code 612, Greenbelt, MD 20771.

E-mail: simone.lolli@nasa.gov produced by Leosphere (Lolli et al. 2011) to complement the historical array of visible (VIS; 523, 527, and $532 \mathrm{~nm}$ ) and eye-safe micropulse lidar instruments (Spinhirne 1993; Spinhirne et al. 1995; Campbell et al. 2002). The integration of these instruments would facilitate the emergence of a denser global network. When possible, collocated UV and VIS lidar profiling would further provide multispectral information on aerosol particle and cloud scattering.

Covering a large fraction of the planet surface at any given time, stratocumulus and stratus clouds play an important role in planetary radiation budget (e.g., Bennartz et al. 2013). These clouds are important because they redistribute the column water liquid content due to the transformation of water falling from clouds into vapor when precipitating (Harrison et al. 1990; O'Connor et al. 
2005). Numerical models require an accurate representation of the microphysical properties of these boundary layer clouds in order to explicitly resolve their impact on climate (Slingo and Slingo 1991; O'Connor et al. 2005). The purpose of this paper is to describe and evaluate a method for measuring light rain and drizzle drop median equivolumetric size diameter $D_{0}$ from collocated MPLNET UV and VIS lidar profiles by taking advantage of the differential backscatter during precipitation at the two wavelengths, respectively. Raindrop size is of particular importance for controlling the rate at which they deposit through the atmosphere and how quickly they evaporate below cloud base (Westbrook et al. 2010).

Though atmospheric lidar profiling is attenuation limited under many common aerosol- and cloud-observing conditions (Sassen and Cho 1992), a scenario exacerbated by liquid water droplet presence given the relatively high scattering cross sections and droplet concentrations (e.g., Sassen 1978), such data have been effectively used for investigating melting-layer thermodynamics and the scattering properties of precipitating low-level liquid water clouds (e.g., Sassen et al. 2005, 2007; Campbell and Shiobara 2008; Di Girolamo et al. 2012). Our goal is to transpose a two-color lidar-based droplet measurement technique designed for infrared bands (IR; Westbrook et al. 2010) to the UV-VIS region and to evaluate performance so as to extend, when possible, MPLNET (http://mplnet.gsfc.nasa.gov) capabilities for studying stratocumulus and stratus cloud precipitation size distributions.

\section{Methods}

The theoretical radar backscattering cross section can be computed from Mie theory (Bohren and Huffman 1983) for homogeneous water spheres. This solution is valid when the raindrop diameter does not exceed $1.0 \mathrm{~mm}$ (Beard 1976) - a value beyond which a raindrop should be otherwise considered oblate. To calculate the theoretical unattenuated lidar backscatter coefficient, precipitation is represented with a gamma-based size distribution (O'Connor et al. 2005; Westbrook et al. 2010) for the number concentration of drops $d_{N}$ with diameters between $D$ and $D+d_{D}$ as

$$
\frac{d_{N}}{d_{D}}\left(N_{0}, D, D_{0}, \mu\right)=N_{0}\left(\frac{D}{D_{0}}\right)^{\mu} \exp \left[-(3.67+\mu) \frac{D}{D_{0}}\right],
$$

where $N_{0}$ controls the total concentration of drops for a given $D_{0}$ and where $\mu$ is the median equivolumetric diameter and the dispersion parameter that controls the shape of the distribution (for $\mu=0$, the distribution reduces to a simple inverse-exponential distribution). This distribution is preferred to log normal when precipitation originates from the melting layer (Willis 1984). The total lidar backscatter for a distribution of water drops (range independent here), neglecting multiple scattering [a reasonable assumption for MPL instruments, given their relatively narrow field of view (Spinhirne 1993), though less so for Leosphere, as discussed further below], is then

$\beta\left(N_{0}, D_{0}, \mu\right)=\frac{1}{4 \pi} \int_{0}^{\infty} \frac{d_{N}}{d_{D}}\left(N_{0}, D, D_{0}, \mu\right) \sigma_{\mathrm{bk}}(D) d_{D}$,

where the backscattering cross section $\sigma_{\text {bk }}$ is calculated using the Mie-based method described by Wolf and Voshchinnikov (2004) that is optimized for relatively large particles with respect to the profiling wavelength and with a complex index of refraction for liquid water droplets of $\left[1.35+i\left(2.4 \times 10^{-9}\right)\right]$ and $[1.33+i(1.6 \times$ $\left.\left.10^{-9}\right)\right]$ at 355 and $527 \mathrm{~nm}$, respectively (Lynch et and Livingston 2001). The values of $\sigma_{\mathrm{bk}}(D)$ are integrated over the size distribution [Eq. (2)] for $D$ and $D_{0}$ ranging in the interval $50-1000 \mu \mathrm{m}$ to compute $\beta$ at both wavelengths.

Shown in Fig. 1 (top) is the backscattering efficiency (or backscattering gain; unitless), $Q_{\mathrm{bkg}}$, solved as

$$
Q_{\mathrm{bkg}}(D)=\frac{\sigma_{\mathrm{bk}}(D)}{\frac{\pi}{4} D^{2}}
$$

for both 355 and $527 \mathrm{~nm}$. Note that $Q_{\mathrm{bkg}}$, computed over a size distribution, can differ greatly at the two wavelengths for a given median equivolumetric diameter $D_{0}$ (Fig. 1, bottom). Shown in Fig. 2 are corresponding extinction efficiency parameters $Q_{\text {ext }}$ [Eq. (4)] (top) and $Q_{\text {ext }}$ computed over a size distribution (at 355 and $527 \mathrm{~nm}$, respectively; bottom) with $\sigma_{\text {ext }}$ the extinction cross section calculated using the same Mie-based method for the backscattering cross section. This term is solved as

$$
Q_{\mathrm{ext}}(D)=\frac{\sigma_{\mathrm{ext}}(D)}{\frac{\pi}{4} D^{2}} .
$$

In contrast to backscatter, $\sigma_{\text {ext }}$ is mostly insensitive to the raindrop diameter, reaching approximately 2, the geometric optical limit, for $D \geq 50 \mu \mathrm{m}$. Then, through the differential backscattering efficiency at the two wavelengths, it is possible to retrieve the median equivolumetric diameter of the precipitation, defining a backscatter color ratio $\left(C_{R} ; \mathrm{dB}\right)$ as 

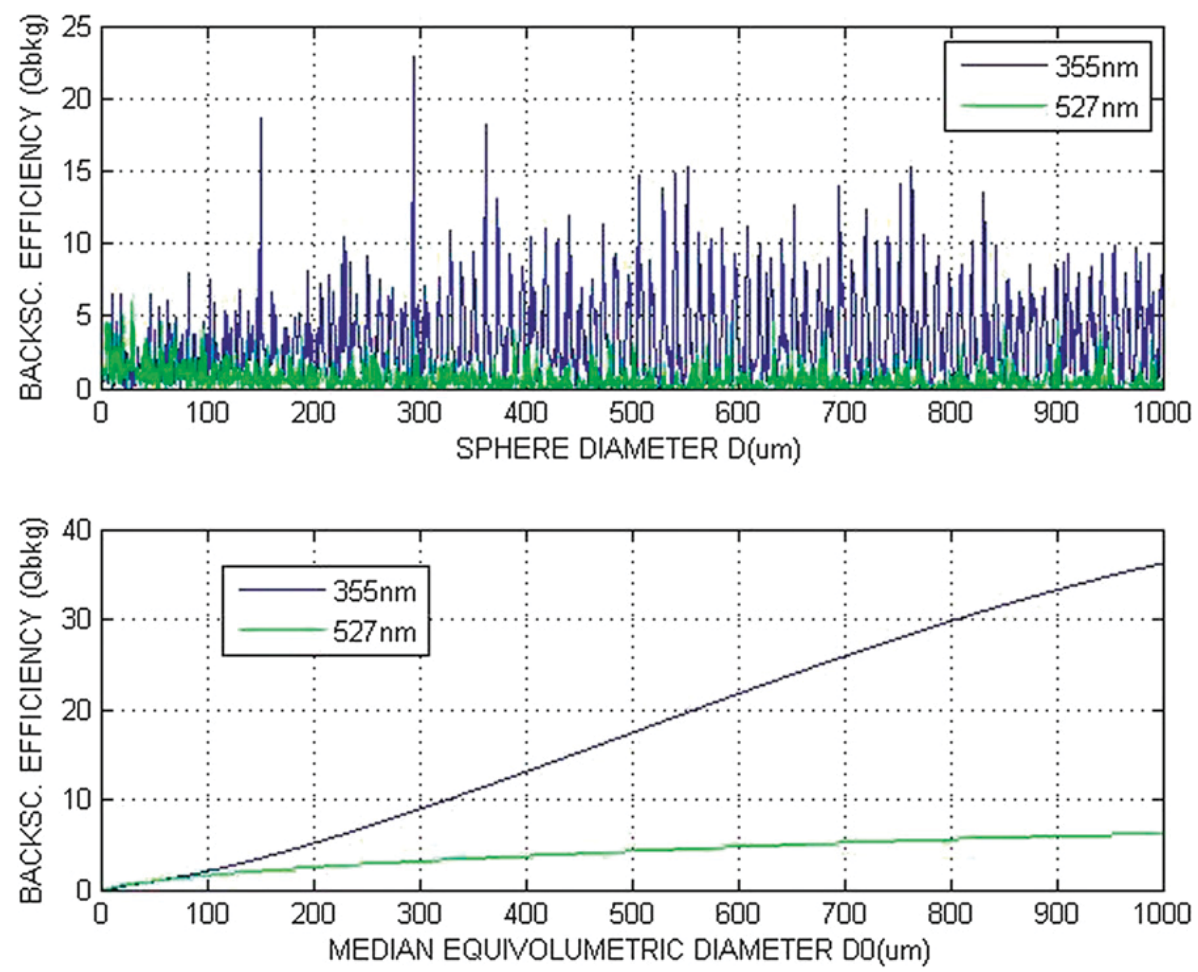

FIG. 1. Lidar $Q_{\text {bkg }}$ as defined in Eq. (3), (top) derived from Mie theory for spherical water drops in 1- $\mu \mathrm{m}$ droplet size intervals and (bottom) $Q_{\mathrm{bkg}}$ computed over a size distribution defined in Eq. (1) with $\mu=2$.

$$
C_{R}\left(D_{0}, \mu\right)=10 \log _{10}\left(\frac{\beta_{355_{\text {rain }}}}{\beta_{527_{\text {rain }}}}\right),
$$

where $\beta_{355_{\text {rain }}}$ and $\beta_{527_{\text {rain }}}$ are the backscattering coefficients due to the rain calculated with Eq. (2) at 355 and $527 \mathrm{~nm}$. As the droplet concentration does not change with the wavelength, $C_{R}$ only depends on the droplet diameter and not on $N_{0}$. Interpreting $C_{R}$ in terms of $D_{0}$ requires some information on the shape of distribution and therefore is sensitive to the value chosen for $\mu$. In Fig. 3, we show profiles for $C_{R}$ solved at $\mu=0,2,4, \ldots, 10$.

Range-dependent normalized attenuated total backscatter coefficient [cf. Eq. (12)] measured by the lidar during precipitation can be substituted into Eq. (5) to estimate $C_{R}(r)$ at any range gate $r$. With $C_{R}$ solved, $D_{0}(r)$ can be estimated. A theoretical $C_{R}$ function is ultimately two dimensional, and thus it can be solved in lookup database form (depicted visually in Fig. 3) and applied as

$$
C_{R_{\text {theor }}}=f\left(D_{0}, \mu\right)
$$

For any measured $C_{R}(r), D_{0}$ is then retrieved, performing a bivariate analysis minimizing the absolute difference between measured and theoretical $C_{R}$ over $D_{0}$ and the dispersion parameter. This bivariate analysis avoids the assumption of the dispersion parameter $\mu$, which is related to the precipitation type:

$$
D_{0}(r)=f^{-1}\left[C_{R_{\text {meas }}}(r), \mu\right] .
$$

Welton and Campbell (2002), Campbell et al. (2003), and Lolli et al. (2011) describe the calibration procedures necessary for retrieving attenuated and corrected backscatter coefficients for MPLNET lidar, including the UV instrument, using an independent measurement of total column aerosol transmission from a nearby sun photometer. During precipitation episodes and cloud presence, however, standard techniques are not possible. Instead, the two signal profiles are normalized to corresponding attenuated molecular scattering profiles, as solved in a precipitation and aerosol particle scattering-free portion of the profile. Assuming that all instrument calibration terms have been accounted for in the processed signal $P(r)$, the total backscatter coefficient $\beta_{\lambda_{\text {tot }}}(r)$ relates as

$$
P_{\lambda}(r) r^{2}=C_{\lambda} O_{\lambda}(r) \beta_{\lambda_{\mathrm{tot}}}(r)\left[T_{\lambda_{\mathrm{tot}}}(r)\right]^{2},
$$

where $C_{\lambda}$ is the linear system calibration coefficient and $\left[T_{\lambda_{\text {tot }}}(r)\right]^{2}$ is the total two-way signal transmission. In the 

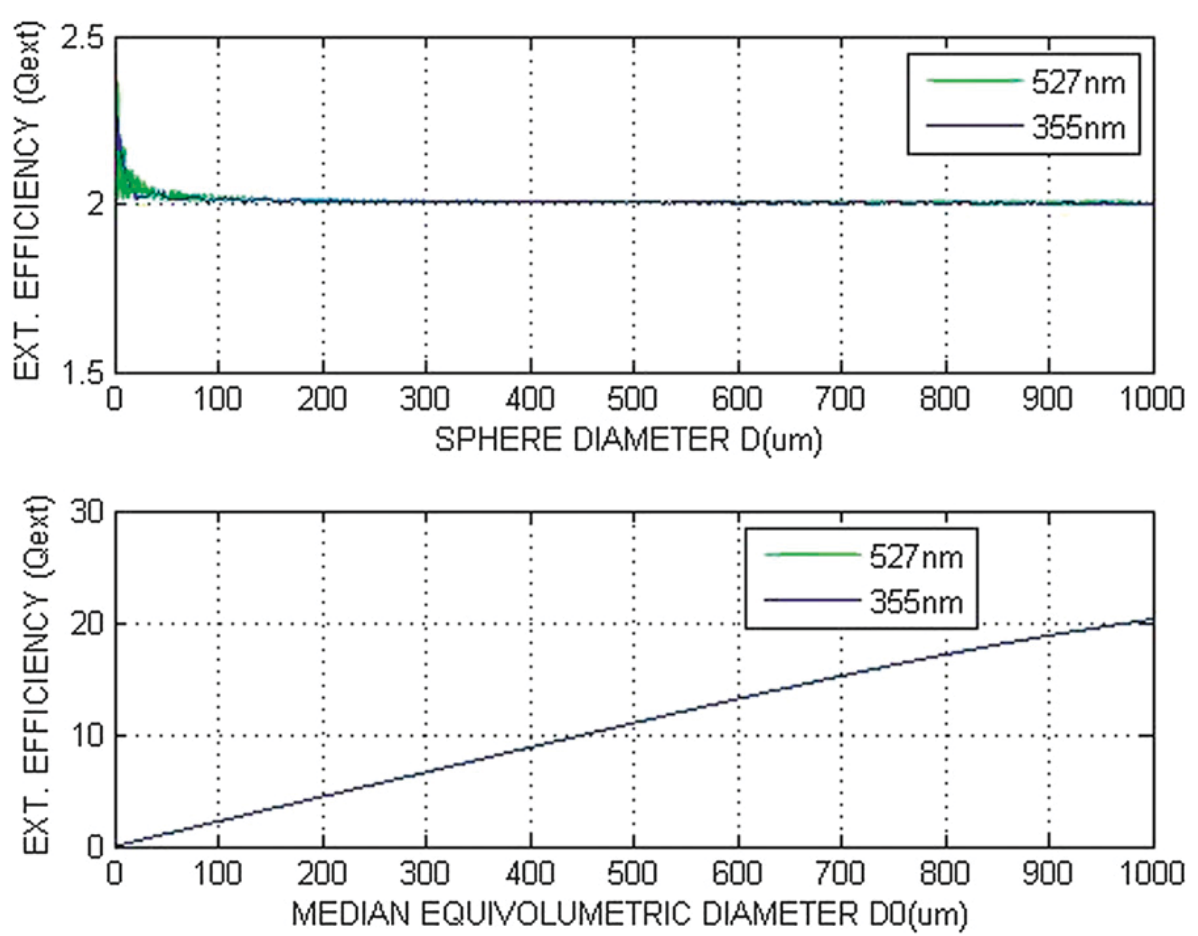

FIG. 2. Corresponding with Fig. $1 Q_{\text {ext }}$ as defined in Eq. (4) (top) derived from Mie theory for spherical water drops in 1- $\mu \mathrm{m}$ droplet size intervals and (bottom) $Q_{\text {ext }}$ computed over a size distribution defined in Eq. (1) with $\mu=2$.

equation, $O_{\lambda}(r)$ is the overlap function, and it equals unity when the field of views of the telescope and laser fully overlap. All terms are with respect to system wavelength. A correction for overlap is needed for MPL instruments (Campbell et al. 2002), as the range at which the full overlap range is reached is much higher than the UV lidar ( $\sim 6.0$ vs $0.35 \mathrm{~km}$; Lolli et al. 2008).
Similar to Eq. (7) of Campbell et al. (2008), however, by normalizing the signal to that of attenuated molecular scattering within a "clear sky" section of the profile (i.e., where total backscatter is exclusively due to molecular scattering), $C_{\lambda}$ in Eq. (8) includes the aerosol transmissivity up to the reference zone. It is possible to define an intermediate value $C_{\lambda}^{*}$ such that

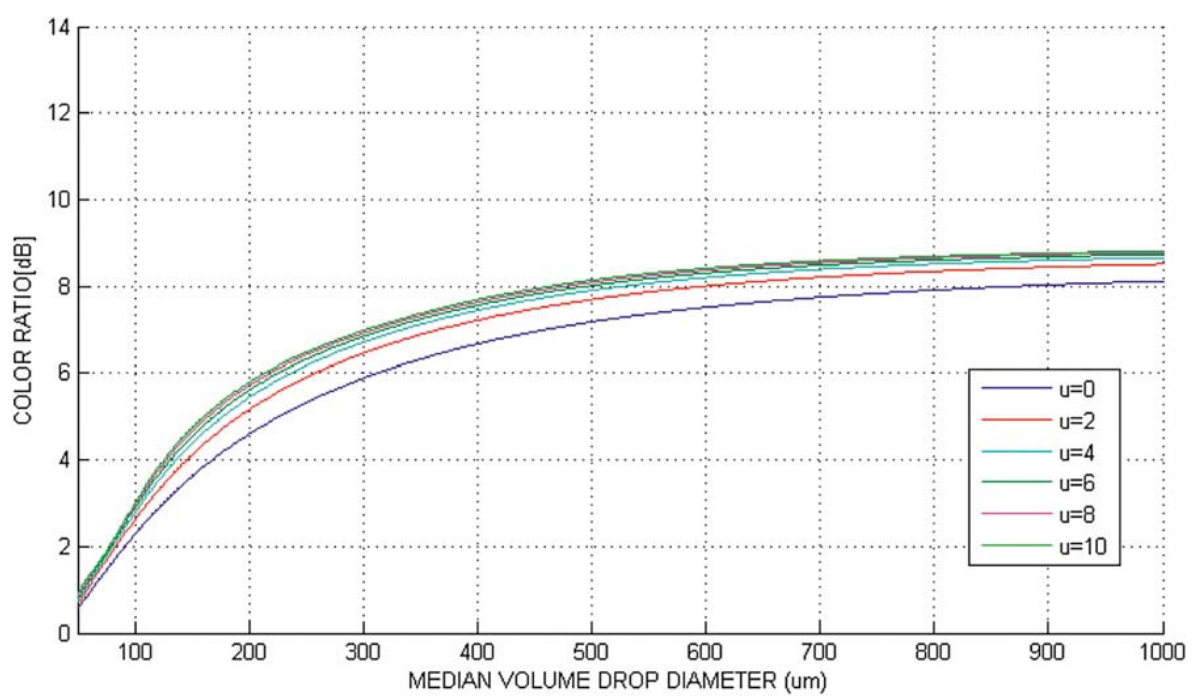

FIG. 3. The 355-/527-nm lidar color ratio, defined in Eq. (5), solved as a function of $D_{0}$. 


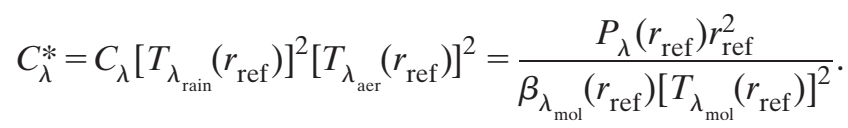

Each signal transmission term is distinguished here as relating either to molecular, rain, or aerosol particle components, and $r_{\text {ref }}$ refers to a rain and aerosol particle scattering-free "clear sky" reference range.
At any point in the profile, the total backscatter coefficient can be estimated from Eqs. (8) and (9) as

$$
\beta_{\lambda_{\text {tot }}}(r)=\frac{P_{\lambda}(r) r^{2}\left[T_{\lambda_{\text {rain }}}\left(r_{\text {ref }}\right)\right]^{2}\left[T_{\lambda_{\text {aer }}}\left(r_{\text {ref }}\right)\right]^{2}}{C_{\lambda}^{*}\left[T_{\lambda_{\text {rain }}}(r)\right]^{2}\left[T_{\lambda_{\text {aer }}}(r)\right]^{2}\left[T_{\lambda_{\text {mol }}}(r)\right]^{2}},
$$

and then the measured $C_{R}$ after the lidar signal calibration is

$$
C_{R}(r)=10 \log _{10}\left(\frac{\left\{\beta_{355_{\text {tot }}}(r)\left[T_{355_{\text {rain }}}(r)\right]^{2}\left[T_{355_{\text {aer }}}(r)\right]^{2}\left[T_{355_{\text {mol }}}(r)\right]^{2}\right\}\left\{\left[T_{527_{\text {aer }}}\left(r_{\text {ref }}\right)\right]^{2}\left[T_{527_{\text {rain }}}\left(r_{\text {ref }}\right)\right]^{2}\right\}}{\left\{\beta_{527_{\text {tot }}}(r)\left[T_{527_{\text {rain }}}(r)\right]^{2}\left[T_{527_{\text {aer }}}(r)\right]^{2}\left[T_{527_{\text {mol }}}(r)\right]^{2}\right\}\left\{\left[T_{355_{\text {rain }}}\left(r_{\text {ref }}\right)\right]^{2}\left[T_{355_{\text {aer }}}\left(r_{\text {ref }}\right)\right]^{2}\right\}}\right) .
$$

\section{$C R$ retrievals and relative measurement uncertainty}

To retrieve $D_{0}$ from Eqs. (5) and (11), the transmission due to aerosol particles and rain and molecular and aerosol backscattering at two different wavelengths must be evaluated. In Eq. (11), for $D_{0} \geq 50 \mu \mathrm{m}$, attenuation due to precipitation or $\left[T_{\lambda_{\text {rain }}}\left(r_{\text {ref }}\right)\right]^{2}$ differs by less than $2 \%$ between the two wavelengths. The transmission term due to the rain then can be simplified. Further, we assume that the aerosol particle mass loading is constant between the time of signal calibration and during the rainfall event. The aerosol transmission is evaluated by retrieving the backscattering coefficient profile at calibration time, inverting the signal with a Fernald method (Fernald 1984), and assuming a fixed value for the ratio of extinction and backscatter cross sections [i.e., the lidar ratio (LR)]. Based on a 10-yr climatological assessment of 527-nm MPLNETderived LR data at the Goddard Space Flight Center (GSFC) during May, we set LR $=50$ sr to derive the extinction coefficient. Significant variability is found within this climatological profile between 40 and 60 sr. This introduces a maximum uncertainty on solutions for the aerosol transmission ratio between $r_{\text {ref }}$ and $r$ of $8 \%$.

Once $\left[T_{\lambda_{\text {aer }}}\left(r_{\text {ref }}\right)\right]^{2}$ and $\left[T_{\lambda_{\text {aer }}}(r)\right]^{2}$ are estimated, $D_{0}$ estimates are independent of aerosol transmission, which further simplifies Eq. (11). From Eqs. (10) and (11), the measure normalized color ratio is

$$
C_{R}(r)=10 \log _{10}\left(\frac{\left\{\beta_{355_{\text {normatt }}}(r)\left[T_{355_{\text {aer }}}\left(r_{\text {ref }}-r\right)\right]^{2}\right\}}{\left\{\beta_{527_{\text {normatt }}}(r)\left[T_{527_{\text {aer }}}\left(r_{\text {ref }}-r\right)\right]^{2}\right\}}\right),
$$

where, for each wavelength, $\beta_{\lambda_{\text {normatt }}}(r)$ is the normalized attenuated backscattering coefficient, defined as

$$
\beta_{\lambda_{\text {norm }_{\text {att }}}}(r)=\frac{\beta_{\lambda_{\text {att }}}(r)}{\beta_{\lambda_{\text {mol }_{\text {att }}}(r)}}=\frac{P_{\lambda}(r) r^{2}}{C_{\lambda}^{*} \beta_{\lambda_{\text {mol }}}(r)\left[T_{\lambda_{\text {mol }}}(r)\right]^{2}},
$$

where $\beta_{\lambda_{\mathrm{att}}}(r)=P_{\lambda}(r) r^{2} / C_{\lambda}^{*}$ is the measured attenuated total backscatter coefficient and $\beta_{\lambda_{\text {mol }_{\text {at }}}}(r)=$ $\beta_{\lambda_{\text {mol }}}(r)\left[T_{\lambda_{\text {mol }}}(r)\right]^{2}$ is the attenuated molecular backscattering coefficient. Normalizing the attenuated total backscattering to the attenuated molecular backscattering (known theoretically) permits making the measurement insensitive to molecular backscattering.

Following the Russell et al. (1979) approach and assuming uncorrelated variables, the measurement uncertainty on $C_{R}(r)$ at each range gate $r$ can be approximated as

$$
\left[\delta C_{R}(r)\right]^{2}=\left[\delta C_{R_{355}}(r)\right]^{2}+\left[\delta C_{R_{527}}(r)\right]^{2},
$$

where

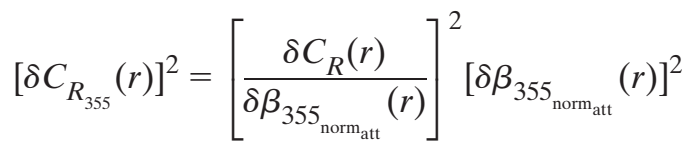

$$
\begin{aligned}
& +\left\{\frac{\delta C_{R}(r)}{\delta\left[T_{355_{\text {aer }}}\left(r, r_{\text {ref }}\right)^{2}\right]}\right\}^{2} \delta\left[T_{355_{\text {aer }}}\left(r, r_{\text {ref }}\right)^{2}\right]^{2}
\end{aligned}
$$

and

$$
\begin{aligned}
{\left[\delta C_{R_{527}}(r)\right]^{2}=} & {\left[\frac{\delta C_{R}(r)}{\delta \beta_{527_{\text {normatt }}}(r)}\right]^{2}\left[\delta \beta_{527_{\text {norm att }}}(r)\right]^{2} } \\
& +\left\{\frac{\delta C_{R}(r)}{\delta\left[T_{527_{\text {aer }}}\left(r, r_{\text {ref }}\right)\right]^{2}}\right\}^{2} \delta\left\{\left[T_{527_{\text {aer }}}\left(r, r_{\text {ref }}\right)\right]^{2}\right\}^{2} .
\end{aligned}
$$

Thus, the total uncertainty in a normalized color ratio contains contributions from the signal measurement 

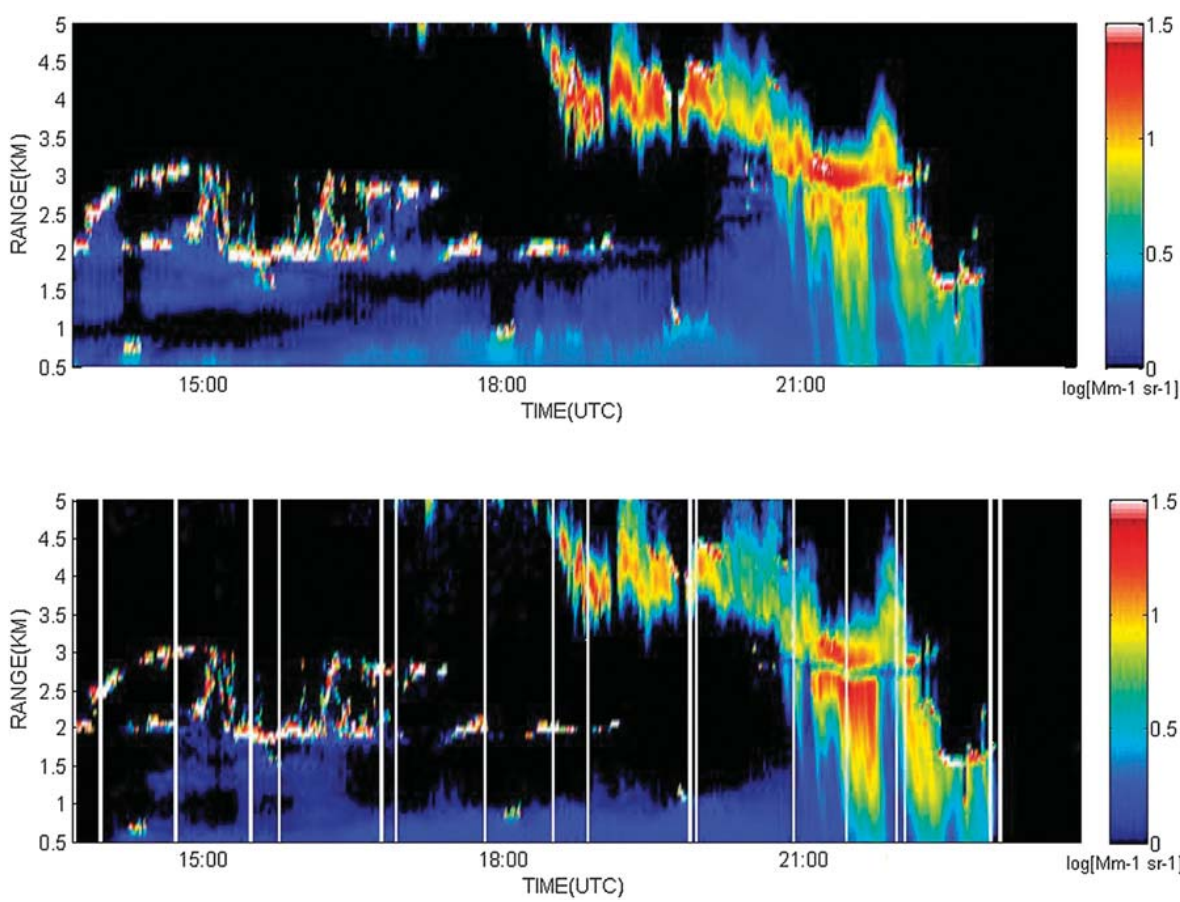

FIG. 4. On 9 May 2012 at NASA GSFC from 0 to $5 \mathrm{~km}$ MSL, MPLNET (top) 527- and (bottom) $355-\mathrm{nm}$ logarithmic normalized attenuated lidar backscatter coefficient $\left[\log \left(\mathrm{Mm}^{-1} \mathrm{sr}^{-1}\right)\right]$ from 1340 to 2359 UTC.

error, the two-way aerosol transmission error, and the density error at both wavelengths.

Substituting the appropriate partial derivatives, we have

$$
\begin{aligned}
{\left[\delta C_{R}(r)\right]^{2}=} & \frac{100}{[\ln (10)]^{2}}\left[\left[\frac{\delta \beta_{355_{\text {norm }}}(r)}{\beta_{355_{\text {norm }}(r)}(r)}\right]^{2}\right. \\
& +\left[\frac{\delta \beta_{527_{\text {norm }}(r)}(r)}{\beta_{527_{\text {norm }}(r)}(r)}\right]^{2}+\left(\frac{\delta\left\{\left[T_{\left.\left.355_{\text {aer }}\left(r, r_{\text {ref }}\right)\right]^{2}\right\}}\right)^{2}\right.}{\left\{\left[T_{355_{\text {aer }}}\left(r, r_{\text {ref }}\right)\right]^{2}\right\}}\right)^{2} \\
& \left.+\left(\frac{\delta\left\{\left[T_{527}(r)\right]^{2}\right\}}{\left\{\left[T_{527_{\text {aer }}}(r)\right]^{2}\right\}}\right)^{2}\right]
\end{aligned}
$$

Concerning the measured normalized attenuated backscatter coefficient, we have

$$
\begin{aligned}
{\left[\frac{\delta \beta_{\lambda_{\text {norm }}}(r)}{\beta_{\lambda_{\text {normatt }}}(r)}\right]^{2}=} & \left\{\frac{\delta\left[P_{\lambda}(r) r^{2}\right]}{P_{\lambda}(r) r^{2}}\right\}^{2}+\left(\frac{\delta C_{\lambda}^{*}}{C_{\lambda}^{*}}\right)^{2} \\
& +\left[\frac{\delta \beta_{\lambda_{\text {mol }}}(r)}{\beta_{\lambda_{\text {mol }}}(r)}\right]^{2}+\left\{\frac{\delta\left[T_{\lambda_{\text {mol }}}(r)\right]^{2}}{\left[T_{\lambda_{\text {mol }}}(r)\right]^{2}}\right\}^{2},
\end{aligned}
$$

where $\lambda$ is 355 and $527 \mathrm{~nm}$.

The uncertainty of the measured range-corrected signal $\delta\left[P_{\lambda}(r) r^{2}\right] /\left[P_{\lambda}(r) r^{2}\right]$ is related to Poisson photoncounting statistics at each range gate $r$ (Campbell et al 2002). The error on lidar constant $\delta C_{\lambda}^{*} / C_{\lambda}^{*}$ is retrieved statistically with a posteriori analysis, and is about $5 \%$. The uncertainty on molecular backscattering results essentially from uncertainties in the molecular density profile. In this paper, the U.S. 1976 (COESA 1976) standard atmosphere model is used and $\delta \beta_{\lambda_{\mathrm{mol}}} / \beta_{\lambda_{\mathrm{mol}}}$ can be limited to about $3 \%$ along the profile.

The error in aerosol transmission $\delta\left[T_{\lambda_{\text {aer }}}\left(r_{\text {ref }}, r\right)^{2}\right] /$ $\left[T_{\lambda_{\text {aer }}}\left(r_{\text {ref }}, r\right)^{2}\right]$ between the range gate at the reference aerosol and rain-free range $r_{\text {ref }}$ and $r$, as previously stated, is assumed to be constant, at about $8 \%$. The uncertainty on molecular transmission is again related to the molecular density models, with $\delta\left[\left(T_{\lambda_{\mathrm{mol}}}\right)^{2}\right] /\left[\left(T_{\lambda_{\mathrm{mol}}}\right)^{2}\right] \approx 10 \%$ (Russell et al. 1979).

The effects of the aerosol contamination to backscattering are discussed further below.

\section{Performance evaluation}

Light rain showers were observed late in the afternoon (starting at 2100 UTC) on 9 May 2012 at the Goddard Space Flight Center in Greenbelt, Maryland $\left[38.99^{\circ} \mathrm{N}, 76.83^{\circ} \mathrm{W} ; 84 \mathrm{~m}\right.$, all heights above mean sea level (MSL)]. Shown in Fig. 4 are the logarithms of the 

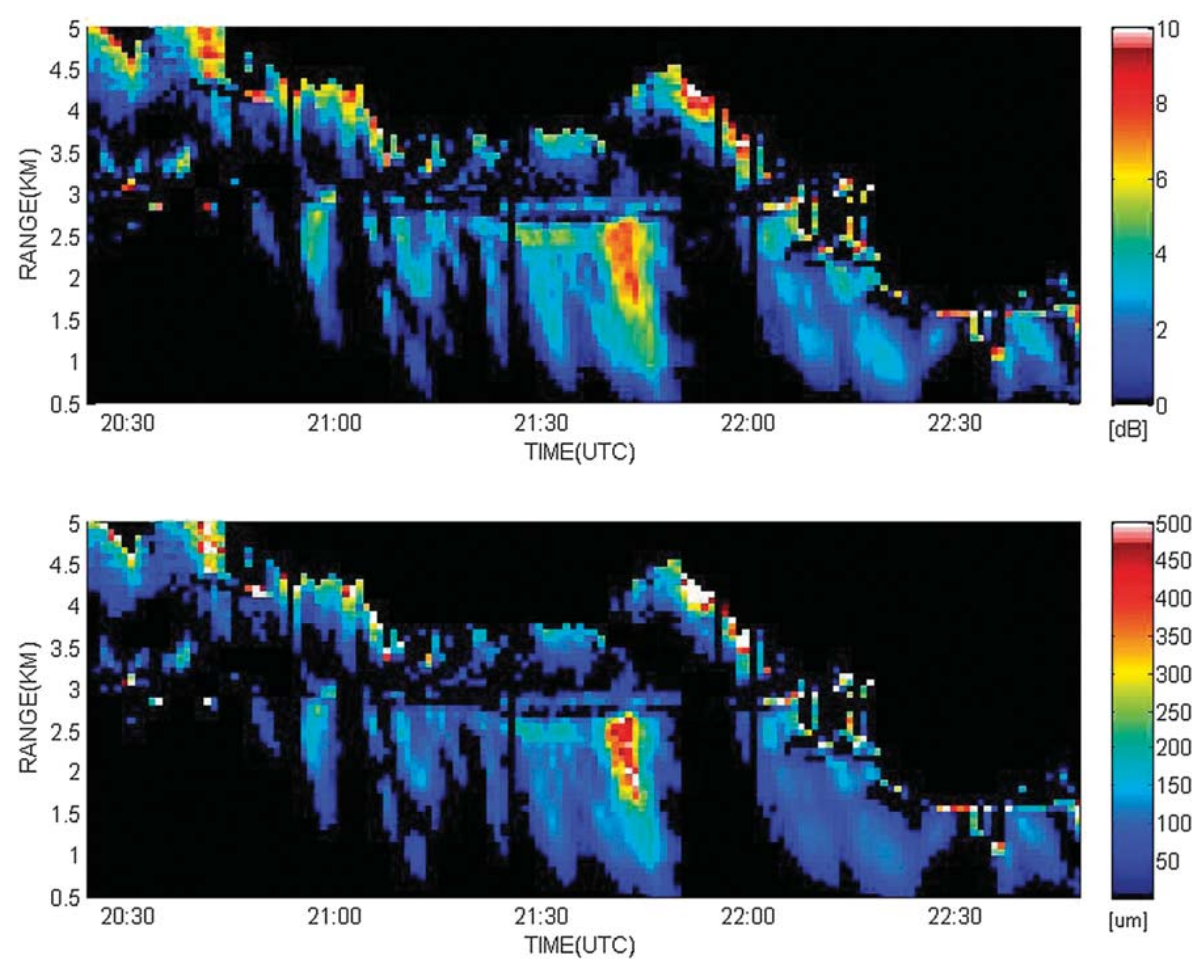

FIG. 5. On 9 May 2012 at NASA GSFC from 0 to 5 km MSL, (top) MPLNET 355-/527-nm backscatter color ratio $(\mathrm{dB})$ and (bottom) retrieved median droplet diameter $(\mu \mathrm{m})$ from 2024 to 2248 UTC.

normalized attenuated VIS and UV MPLNET lidar backscatter [Eq. (13)] composites for 1340-2359 UTC, respectively. Both instruments recorded data at 60 -s temporal and 75-m vertical resolutions. The cloud base is shown lowering in both profiles from 5.0 to $3.0 \mathrm{~km}$, with light rain first appearing near 2100 UTC (Fig. 4). The melting layer remains constant in height through the period; this is also confirmed by Dulles International Airport $\left(38.9^{\circ} \mathrm{N}, 77.45^{\circ} \mathrm{W} ; 95 \mathrm{~m}\right)$ radiosonde isotherm at $0^{\circ} \mathrm{C}$, at about $3.1 \mathrm{~km}$. A lidar dark band (e.g., Sassen et al. 2005; Di Girolamo et al. 2012) appears in both profile composites near $2.9 \mathrm{~km}$, indicating a cold rain process as the precipitation originates from melting ice. Signal normalization was conducted above $3.0 \mathrm{~km}$ from 1900 to 2000 UTC (60 1-min-averaged profiles).

After 2100 UTC, precipitating fall streaks are distinct in both signal composites. From calculations described in section 2, backscatter signal profiled from precipitation at $355 \mathrm{~nm}$ is greater than at $527 \mathrm{~nm}$. Composite depictions of $C_{R}$ and $D_{0}$ from 2024 to 2248 UTC are shown in Fig. 5 . In the cloud layer, $C_{R}$ is roughly $0 \mathrm{~dB}$, meaning that for cloud droplets $(<30 \mu \mathrm{m}$ in diameter) attenuation due to scattering is effectively the same at both wavelengths. The derived $C_{R}$ from clear sky (molecular scattering only), being the attenuated backscattering profiles normalized to the attenuated molecular backscattering, is about $0 \mathrm{~dB}$.
The value of $D_{0}$ is retrieved through bivariate analysis. The range of retrieved $D_{0}$ values shown (Fig. 5, bottom) is consistent with light rain and drizzle, sized between 100 and $500 \mu \mathrm{m}$ (e.g., Frisch et al. 1995).

Figure 6a shows how the uncertainty relative to the color ratio (profile taken at 2143 UTC), calculated using Eqs. (14)-(18), translates into uncertainty in $D_{0}$ retrieval (Fig. 6b). The uncertainty in the $C_{R}$ is mostly dominated by error in lidar measurement and degrades as the signal-to-noise ratio. The error in $D_{0}$ is instead related to the unknown drop size spectrum (parameter $\mu$ ) and directly to the shape of the theoretical $C_{R}$ [Eq. (5); Fig. 3] that flattens as the raindrop diameter increases: the uncertainty is then bigger for larger drops (near $50 \%$ for $600 \mu \mathrm{m}$, Fig. 6b).

\section{Errors because of multiple scattering and aerosol returns}

Though the 527-nm MPL instrument features a very narrow field of view, the UV lidar design includes one order of magnitude larger, and thus multiple scattering effects must be taken into account. O'Connor et al. (2004) evaluate the multiple scattering effect for a UV lidar with similar optical characteristics in a liquid water cloud consisting of relatively small droplets. Considering some slight differences between the two UV lidars, multiple scattering was found to reach a maximum $15 \%$ 
a)

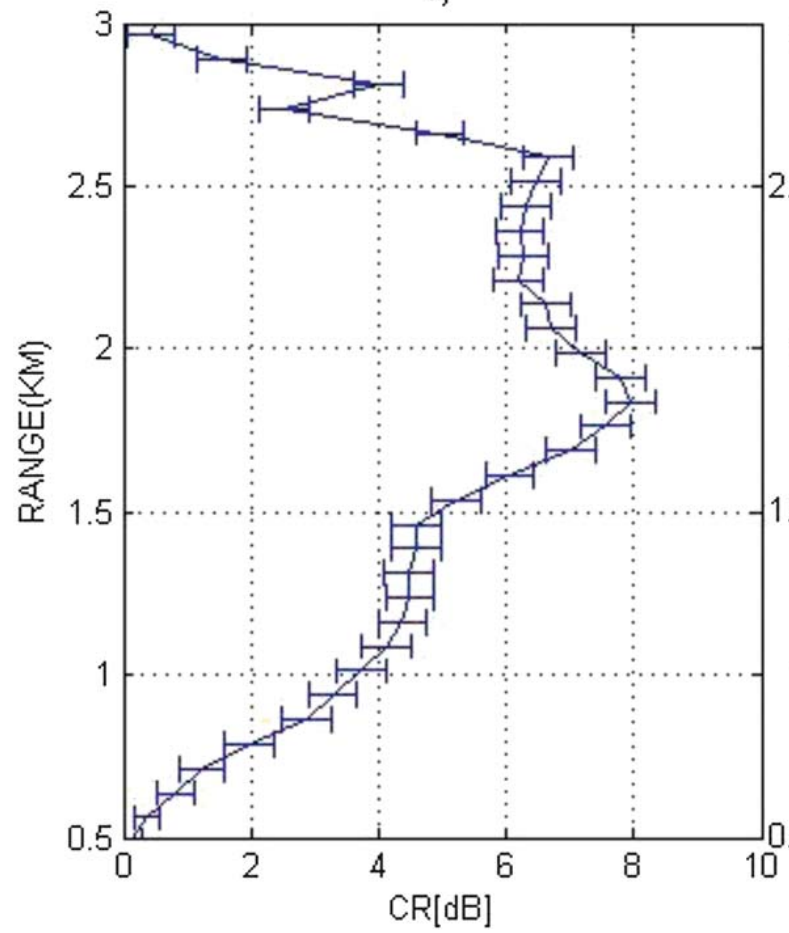

b)

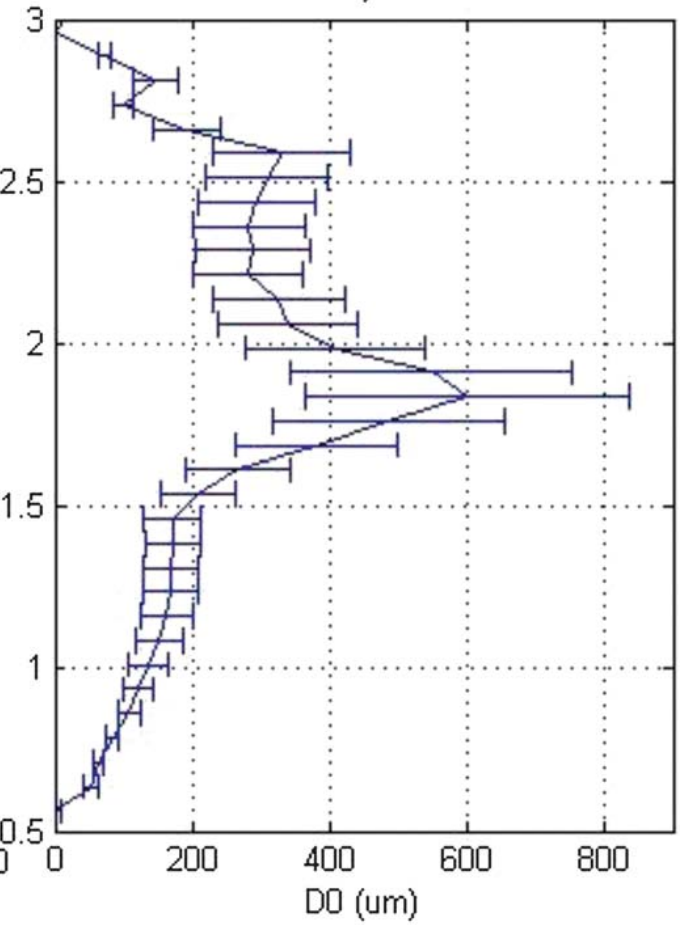

FIG. 6. (a) Measured $C_{R}$ profile at 2143 UTC with relative uncertainty. (b) Retrieved $D_{0}$ from $C_{R}$ profile and relative uncertainty. As the theoretical $C_{R}$ flattens, increasing the raindrop diameter, the uncertainty is bigger for larger drops, near $50 \%$ for $600 \mu \mathrm{m}$.

at roughly $1 \mathrm{~km}$ under heavy drizzle conditions. This is an extreme case, and being that the attenuated backscattering coefficients in rain are lower than $30 \mathrm{Mm}^{-1} \mathrm{sr}^{-1}$, a value of $10 \%$ for the multiple scattering is more likely. This static value has been applied for solving Eq. (12).

At $355 \mathrm{~nm}$, backscatter from aerosols is at least one order of magnitude smaller than that from precipitation. At $527 \mathrm{~nm}$, the smaller backscattered power from precipitation may be comparable to the returns from the aerosol particles, especially in the boundary layer. This will lead to $D_{0}$ being underestimated. We estimate the aerosol return by looking at precipitation-free areas of the boundary layer in Fig. 4 (top). The ratio of precipitation to aerosol backscattered power is 5:1. For a measured color ratio of $4 \mathrm{~dB}$, the retrieved median equivolumetric drop size is $D_{0}=140 \mu \mathrm{m}$. In this situation, the aerosol backscattered power accounts for onefifth of the signal and the true ratio for the rain signal alone would be $4.6 \mathrm{~dB}$, corresponding to a true value for the raindrop size of $D_{0}=162 \mu \mathrm{m}$. This value is taken into account to retrieve the correct $D_{0}$ in the aerosolcontaminated pixels mostly in the boundary layer.

When considering each of the aforementioned sources of algorithm uncertainty, in tandem with that due to signal processing, solutions for $D_{0}$ correspond with a maximum total uncertainty of roughly $50 \%$. Though this is a considerable amount of relative error, it still implies that there is some reasonable measure of skill exhibited by the technique. Recall that, on most rainy days, continuous lidar profiling measurements are almost immediately discarded from the negative impact of source pulse attenuation. Thus, the potential use of MPLNET measurements for estimating $D_{0}$, and with the thought that some uncertainty could be reduced with continuing instrument improvements and more stable calibrations, is encouraging.

\section{Conclusions}

In this paper, collocated ultraviolet and visible (355 and $527 \mathrm{~nm}$, respectively) lidar measurements are used to estimate the precipitation drop median equivolumetric diameter $D_{0}$ over a 3-h period of light rain showers profiled at the NASA Micropulse Lidar Network (MPLNET)-observing site at the Goddard Space Flight Center in Greenbelt, Maryland, on 9 May 2012. Scattering calculations are performed for spherical liquid drops from light rain samples using Mie theory to link $D_{0}$ to the ratio of backscatter signals at the two wavelengths. These calculations are then applied to retrieve $D_{0}$ within precipitating fall streaks, such that signal attenuation effects are not limiting, including the 
parent cloud layers to the extent of their profiling depth.

We estimate that total error in solutions for $D_{0}$ is at about $50 \%$ for larger raindrops. The primary sources of uncertainty in the retrieval are attributable to the lidar signal measurement and the unknown shape of raindrop size distributions. Molecular and aerosol scattering contributions and relative transmission losses due to the various atmospheric constituents were evaluated to derive $D_{0}$ from the observed color ratio profiles. Multiple scattering is important for the UV lidar, but it exhibits lower overall uncertainty with respect to other error sources identified.

Westbrook et al. (2010) describe the basis for the methodology investigated here. We find that transposing their technique from the near infrared to the UV-VIS region increases retrieval uncertainties; that is, the two wavelengths ( 355 and $527 \mathrm{~nm}$ ) are relatively close, and the color ratio curve shapes become flat, especially for large drops $(>500 \mu \mathrm{m})$, which increase relative error.

Despite this, the demonstration of this method shows that the technique exhibits reasonable skill. With knowledge of $D_{0}$, higher moments of the drizzle droplet distribution, including liquid water content and rainfall rate, can be further estimated, which will add value to the retrieval overall. At that stage, a value-added MPLNET product reporting these parameters for light rain events can be considered, with the goal of an improved understanding of the microphysics and physical scattering properties of precipitation at near-visible wavelengths from global ground-based measurements.

Acknowledgments. The Micropulse Lidar Network is coordinated through the support of the NASA Radiation Sciences Program. The authors gratefully acknowledge the University of Wyoming's Department of Atmospheric Sciences for access to its radiosonde visualization tools. Author JRC acknowledges the support of NASA Interagency Agreement NNG12HG05I on behalf of the Micropulse Lidar Network.

\section{REFERENCES}

Beard, K. V., 1976: Terminal velocity and shape of cloud and precipitation drops aloft. J. Atmos. Sci., 33, 851-864.

Bennartz, R., and Coauthors, 2013: July 2012 Greenland melt extent enhanced by low-level liquid clouds. Nature, 496, 83-86, doi:10.1038/nature12002.

Bohren, C. F., and D. R. Huffman, 1983: Absorption and Scattering of Light by Small Particles. John Wiley and Sons, 530 pp.

Campbell, J. R., and M. Shiobara, 2008: Glaciation of a mixedphase boundary layer cloud at a coastal arctic site as depicted in continuous lidar measurements. Polar Sci., 2, 121-127.

—, D. L. Hlavka, E. J. Welton, C. J. Flynn, D. D. Turner, J. D. Spinhirne, V. S. Scott, and I. H. Hwang, 2002: Full-time, eye-safe cloud and aerosol lidar observation at Atmospheric Radiation Measurement Program sites: Instrument and data processing. J. Atmos. Oceanic Technol., 19, 431-442.

, E. J. Welton, J. D. Spinhirne, Q. Ji, S.-C. Tsay, S. J. Piketh, M. Barenbrug, and B. N. Holben, 2003: Micropulse lidar observations of tropospheric aerosols over northeastern South Africa during the ARREX and SAFARI 2000 dry season experiments. J. Geophys. Res., 108, 8497, doi:10.1029/ 2002JD002563.

_, K. Sassen, and E. J. Welton, 2008: Elevated cloud and aerosol layer retrievals from micropulse lidar signal profiles. J. Atmos. Oceanic Technol., 25, 685-700.

COESA, 1976: U.S. Standard Atmosphere, 1976. NOAA, 227 pp.

Di Girolamo, P., D. Summa, M. Cacciani, E. G. Norton, G. Peters, and Y. Dufournet, 2012: Lidar and radar measurements of the melting layer: Observations of dark and bright band phenomena. Atmos. Chem. Phys., 12, 4143-4157.

Fernald, F. G., 1984: Analysis of atmospheric lidar observations: Some comments. Appl. Opt., 23, 652-653.

Frisch, A. S., C. W. Fairall, and J. B. Snider, 1995: Measurement of stratus cloud and drizzle parameters in ASTEX with a $\mathrm{K} \alpha$ band Doppler radar and a microwave radiometer. J. Atmos. Sci., 52, 2788-2799.

Harrison, E. F., P. Minnis, B. R. Barkstrom, V. Ramanathan, R. D. Cess, and G. G. Gibson, 1990: Seasonal variation of cloud radiative forcing derived from the Earth Radiation Budget Experiment. J. Geophys. Res., 95 (D11), 18687-18704.

Hoff, R., and J. Boesenberg, 2008: GAW Aerosol Lidar Observations Network (GALION). Preprints, Symposium on Recent Developments in Atmospheric Applications of Radar and Lidar, New Orleans, LA, Amer. Meteor. Soc., 5.2. [Available online at https://ams.confex.com/ams/88Annual/techprogram/ paper_131629.htm.]

Lolli, S., L. Sauvage, I. Stachlewska, and R. Coulter, 2008: Assessment of the EZ LIDAR and micro pulse lidar (MPL) performances at ARM Southern Great Plains (SGP) Central Facility for the measurement of clouds and aerosols. Geophysical Research Abstracts, Vol. 10, Abstract EGU2008A-11091. [Available online at http://www.cosis.net/abstracts/ EGU2008/11091/EGU2008-A-11091.pdf.]

— _ - - S. Loaec, and M. Lardier, 2011: EZ lidar: A new compact autonomous eye-safe scanning aerosol lidar for extinction measurements and PBL height detection. Validation of the performances against other instruments and intercomparison campaigns. Opt. Pura Apl., 44, 33-41.

Lynch, D. K., and W. Livingston, 2001: Color and Light in Nature. 2nd ed. Cambridge University Press, 277 pp.

O'Connor, E. J., A. J. Illingworth, and R. J. Hogan, 2004: A technique for autocalibration of cloud lidar. J. Atmos. Oceanic Technol., 21, 777-786.

— R. J. Hogan, and A. J. Illingsworth, 2005: Retrieving stratocumulus drizzle parameters using Doppler radar and lidar. J. Appl. Meteor., 44, 14-27.

Russell, P., T. Swissler, and M. McCormick, 1979: Methodology for error analysis and simulation of lidar aerosol measurements. Appl. Opt., 18, 3783-3797.

Sassen, K., 1978: Backscattering cross sections for hydrometeors: Measurements at $6328 \AA$ A. Appl. Opt., 17, 804-806.

— , and B. S. Cho, 1992: Subvisual-thin cirrus lidar dataset for satellite verification and climatological research. J. Appl. Meteor., 31, 1275-1285.

_ J. R. Campbell, J. Zhu, P. Kollias, M. Shupe, and C. Williams, 2005: Lidar and triple-wavelength Doppler radar measurements 
of the melting layer: A revised model for dark- and brightband phenomena. J. Appl. Meteor., 44, 301-312.

_ S. Matrosov, and J. Campbell, 2007: CloudSat spaceborne $94 \mathrm{GHz}$ radar bright bands in the melting layer: An attenuationdriven upside-down lidar analog. Geophys. Res. Lett., 34, L16818, doi:10.1029/2007GL030291.

Slingo, A., and J. M. Slingo, 1991: Response of the National Center for Atmospheric Research Community Climate Model to improvements in the representation of clouds. J. Geophys. Res., 96 (D9), 15341-15357.

Spinhirne, J. D., 1993: Micro pulse lidar. IEEE Trans. Geosci. Remote Sens., 31, 48-55.

— J. A. R. Rall, and V. S. Scott, 1995: Compact eye safe lidar systems. Rev. Laser Eng., 23, 112-118.

Welton, E. J., and J. R. Campbell, 2002: Micropulse lidar signal uncertainties. J. Atmos. Oceanic Technol., 19, 2089-2094.

, — - J. D. Spinhrine, and V. S. Scott III, 2001: Global monitoring of clouds and aerosols using a network of micropulse lidar systems. Lidar Remote Sensing for Industry and Environment Monitoring, U. N. Singh, T. Itabe, N. Sugimoto, Eds. International Society for Optical Engineering (SPIE Proceedings, Vol. 4153), 151-158.

— - and Coauthors, 2002: Measurements of aerosol vertical profiles and optical properties during INDOEX 1999 using micropulse lidars. J. Geophys. Res., 107, 8019, doi:10.1029/ 2000JD000038.

Westbrook, C. D., R. J. Hogan, E. J. O'Connor, and A. J. Illingworth, 2010: Estimating drizzle drop size and precipitation rate using two-colour lidar measurements. Atmos. Meas. Tech., 3, 671-681, doi:10.5194/amt-3-671-2010.

Willis, P. T., 1984: Functional fits to some observed drop size distributions and parameterization of rain. J. Atmos. Sci., 41, $1648-1661$.

Wolf, S., and N. V. Voshchinnikov, 2004: Mie scattering by ensembles of particles with very large size parameters. Comput. Phys. Commun., 162, 113-123. 